\title{
Modality: teaching grammar through discourse
}

\author{
N. Filippova \\ Admiral Makarov National University of Shipbuilding \\ Corresponding author. E-mail: nina.filippova@nuos.edu.ua \\ Paper received 31.01.20; Accepted for publication 12.02.20.
}

\section{https://doi.org/10.31174/SEND-Ph2020-217VIII65-03}

\begin{abstract}
The current and urgent need in Academic English to re-format the process of teaching grammar within the framework of forming communicative competence at the discourse level is emphasized. Authentic texts illustrate a variety of discourses based on the modality forms and structures. The author tries to attract the attention to the fact that the sentence-based view of grammar is outdated and inconsistent with the notion of communicative competence including linguistic (grammatical) competence and discourse competence (CEFR).
\end{abstract}

Keywords: modality, discourse, Academic English, communicative competence.

Modal - Logic (of a proposition) which involves the affirmation of possibility

impossibility, necessity or contingency.

The Oxford English Reference Dictionary

Necessity! Thou mother of the world

$$
\text { P.B. Shelley }
$$

The purpose of the paper is to offer some particular ideas to take modality from the field of theory and put it into pedagogical use in the academic English environment. The paper examines the distribution of the English modal expressions in the text of the international document (Quality management systems - Requirements ISO 9001:2015) and Edwin Brock's poem "The Curtain Poem". The study first shows the universally acknowledged modal meanings; it then illustrates how discourse-centred teaching programs can use the appropriate linguistic data in teaching to increase student's grammatical awareness.

At present communicative competence is known to be the foundation of communicative language teaching; it is extremely significant that we have to move beyond the sentence level; we have to make our students understand the relationship between the morphological and syntactical aspects of linguistic competence (e.g. modality) and some sociolinguistic and pragmatic aspects of academic discourse competence [2]. Even now there exist two contrastive ideas: 1) grammar is context-free; 2) grammar is almost completely context-dependent. The majority of grammatical rules depend on the particular logical and pragmatic meaning, situational context and, of course, discourse context. Modality is considered one of the most sensitive grammatical topics, the others being, for example, tense - aspect - mood - voice alternatives or article (determiner) choice. A short overview of the earliest publications should include the studies of formal linguists, e.g. N. Chomsky [3] and functional linguists, e.g. Givón [4; 5] or Halliday and Hasan [6].

The paper is entitled "Modality: teaching grammar through discourse" because the best context for teaching modality is text. By text, we mean coherent and integer linguistic unit of any type (conversational, narrative, academic, mass media) which is realized in a particular form having particular composition, consisting of special elements, Generally speaking, text is a composition having a pragmatic aim. By discourse, we mean the process of verbal communication: it is a coherent text in combination with extralinguistic (pragmatic, sociocultural, psycho- logical) factors; it is a component of interaction of humans and their consciousness (cognitive processes).

One might object that texts are long and diffused and that any number of isolated examples can be lined up in less time and space in exercises (sentences). However, the use of texts is ultimately efficient. Firstly, they contain factual information. Secondly, they illustrate the evidence of actual language use and contemporary distribution of frequent forms. Thirdly, texts are contributions to discourses and, in this way, they demonstrate real functioning of the forms in different genres for different aims of their authors. Fourthly, in present-day classroom studentcentred environment it is important to adapt teaching materials to different levels of students and to different rates of their progress because texts provide wider access to all students by providing some positive evidence for everyone and by focusing not only on a single structure but on the wider context of its functioning. Fifthly, using texts/discourses enables to make teaching compatible with the formation of communicative competence because texts/discourses are viewed as units of communication.

The ideas outlined above are far from being revolutionary it is universally acknowledged: texts provide additional input to learners, and their benefits have been discussed and justified for 30 years. There are many examples of wonderful grammar books which authors have brilliantly introduced the theory into practice (in our case, context) [8].

In this paper we would like to attract the attention to one particular case of teaching modality of necessity and obligation through the following discourses:

1) ISO 9001:2015 International Standard: "Quality management systems - Requirements";

2) Edwin Brock's poem "The Curtain Poem".

The ISO publication is an international standard which aim is to regulate the understanding of the organization and its context, quality management system and its processes, organizational rules, responsibilities and authorities, quality objectives and planning, resources, necessary documented information, operational control, performance evaluation and continual improvement. The authors of this international document who take part in its developing and preparing include technical committees, international governmental and non-governmental organizations collaborate closely because each member is interested in the subject. It is extremely important for graduates to comprehend the essence of quality management for Ukraine. 
Moreover, it is extremely useful to discuss the related topics for particular communicative situations.

The author of the poem Edwin Brock (1927-1997), is the well-known British poet who published ten volumes of poetry from 1959 to 1997 and whose two poems "Five Ways to kill a Man" (1972) and "Song of the Battery Hen" (1977) have been heavily anthologized. As far as his personal life is concerned, it is known that he was married twice (N.V. Weller: 1949-1964 and E. Skilton: 19671997). It is known that "the traumatic experience of marital conflict and divorce permeated his poetry at the time" (Wikipedia). "The Curtain Poem" was published in 1960. It is useful for discussing family topics in class.

In general, modality characterizes any utterance, expresses the subjective attitude of a speaker, creates the potentialities for personal self-expression, i.e. to express personal emotions, moods, intentions, convictions. Modality serves as an instrument for exchanging personal evaluations of the situation which is embedded into the addresser's communicative intention his/her intentional or intuitive target, thus the selection of the means of selfexpression being dependent on the appropriate intention and stipulating the communication vector.

Modality as the general language category is based on the fact of the language as the system and is realized in a number of language categories: e.g. mood, modal verbs. There are two types of modality: objective and subjective, the latter implying obligatory evaluation. Linguistically, objective modality is revealed in a wide use of passive constructions (there is even a special term "passivigation" of mass media language). Traditionally modals and modal expressions are grouped into three major categories according to their main meanings: permission/possibility/ability; obligation/necessity; volition/prediction [1, p. 475]. Each modal can have two different types of meaning: intrinsic (actions and events that agents directly control: permission, obligation, volition) and extrinsic (logical essence of events, assessment of likelihood: possibility, necessity, prediction. In the framework of the article we concentrate on the modals of obligation/necessity which are usually presented in the textbooks, manuals and reference books according to the degree of obligation/necessity: 1) absolutely necessary/obligatory: must, have to; 2) expected: be supposed to; 3) advised: should, ought to, shall, had better; 4) suggested: could, might.

Frequency of modals and semimodal across registers show that the modals should, must, shall are not extremely common (in contrast to will, would, can, could, may). Must and should are relatively common in academic prose [8].

The main problem in teaching modality of obligation/necessity to Ukrainian and Russian consists in the fact that in these languages there is one universal modal word which can be used for any situation (absolutely necessary, expected, advised or suggested) having the generalized and "washed-out" meaning "it is necessary or it is required". Learners apparently have more difficult with differentiating the meaning and use of so many modals of obligation and necessity: situating the use of particular English modals is difficult for learners. One way for teachers to help learners is to use texts for highlighting meaning - use associations which provides com- municative input lacking in traditional presentations of obligation/necessity modals, which provides communicative input lacking in traditional presentations.

As this language category cannot be analysed separately from text creators because any text is a construct generated by a communicator and intended for another communicator, we deal with the term "discourse".

Discourse modality can be presented, in a simplified way, as the hierarchy of the following levels: 1) addresser's modivational modality; 2) fact modality; 3) impacting modality. By motivational modality, we mean that the addresser adapts the structural and meaningful scheme of the text to the communicative situations in which the texts are functioning, i.e. text functionality based on pragmatic direction of interpersonal relationships. By fact modality, we mean that the text always contains some scope of factual information about the reality and some cognitive system of conceptual elements which includes the addresser's knowledge and experience. By impacting modality, we mean the direct connection between the addresser and the addressee through the text as the means of transferring the information and impacting its interpretation.

Fiction and media texts/discourses need and contain a variety of explicit and implicit linguistic means of expressing opinions and evaluation, including:

1) use of words and collocations with negative or positive collocations;

2) use of lexical and syntactical stylistic devices (e.g. similes, metaphors, repetitions, rhetorical questions);

3) use of modal verbs and expressions.

Thus the range of linguistic potentialities for expressing modality (attitude to the reality, events) is extremely wide and practically includes the whole specter of phonetical, graphical, lexical phraseological and syntactical means. The fact is that academic or document texts do not presuppose their interpretation, comments or evaluation. They do not contribute to forming any ideological background in contrast to mass media texts with their capability of impacting both social and personal conscience by means of ideologized concepts and interpretations reflecting particular systems of values and relationships.

Motivational modality. The basis of the structure of the text of an international document is the discrete sense structure of the text coded with continuous information impregnating all the text constituents:

If these texts' motivational modality is implicit, their implicities being built into the text semantic structure which, in this ISO document, is expressed in the Introduction:

"The adoption of a quality management system is a strategic decision for an organization that can help to improve its overall performance and provide a sound basis for sustainable development initiatives. The potential benefits to an organization of implementing a quality management system based on this International Standard are: a) the ability to consistently provide products and services that meet customer and applicable statutory and regulatory requirements; b) facilitating opportunities to enhance customer satisfaction; c) addressing risks and opportunities associated with its context and objectives; d) the ability to demonstrate conformity to specified quality management system requirements" [7; p. VI]. 
Motivational modality of another sample text is explicit because the addresser is a definite author whose intention is to express his idea of an ideal wife because it may be written some years before his "hard" divorce with his first wife.

\section{THE CURTAIN POEM}

A home should have a wife, a cat and blinds upon the windows that when pulled aside are suddenly drawn back again. A wife should have a cat to kick a home to love and, if I have not made my meaning, plain, a curtain to be drawn aside and suddenly pulled back again.

A man should have a wife to love a home to kick and cats upon the curtains which he may from time to time refrain from seizing to and back again

But if a home should have a man who waits upon a window-sill endeavoring to find a plan

for all that moves outside the pane be sure the home will have a wife perhaps the wife will have a cat but if by now my meaning is not plain the wife in all sincerity should turn her back upon the scream and, singing, seize the cloth across again.

Fact modality. Fact modality of the ISO document is expressed in the text composition which comprises Introduction, 10 chapters, 2 Annexes and Bibliography, each having its social loading.

Fact modality od Brock's poem is, in its turn, is stipulated by his life and marriage individual experience which he is sharing with his readers. Cognitive background is polysemantic and cognitive modality is explicit and relates both to the knowledge and to the knowledge of communicative situation.

Impacting modality. The poem is characterized by monomodality, recommendation or advice is explicitly expressed by the author and does not change throughout the text. The addresser is very much personal and even intimate in confiding with his addresses. Monomodality of the document is differentiated and is expressed by necessity/obligation modals shall (136 cases), should (2 cases), may (4 cases) and can (76 cases): shall for indicating a requirement; should for indicating a recommendation; may for indicating a permission; can for indicating a possibility or a capability. It is specifically clarified in Introduction (Section O.I. General).

There are some examples: "The procedures used to develop this document and those intended for its further maintenance are described in the ISO/IEC Directives, Part 1. In particular the different approval criteria needed for the different types of ISO documents should be noted"; "The organization shall monitor and review information about these external and internal issues."

Moreover the authors use need when they indicate potential, slight obligation or modal expressions: to be bound, to be required. Emotive element of impacting modality is rather explicit in the poem as the addressee is considered by the addresser is the obligatory component of communication through this discourse. As the addressee is implicit for the ISO document, the emotive element of modality is impregnated into the document and is shown in the above-mentioned modal means.

The simplibied scheme of the Activities presupposed for effective teaching imply using discourses to contextualize the difference in modal meanings and the role modals play in discourse structures is as follows:

1) to analyse the type of the discourse, addressers, their communicative goals, illocutions, expected outcomes, communicative situations which are typical for this discourse;

2) to direct the learner's attention to different modal forms and to different modal meanings: it is important to associate form and meaning;

3 ) to constrast the meaning of the modal and its function in the text: e.g. shall and can;

4) to elicit students to make their own comments, recommendations, prohibitions etc. describing the communicative situation and explaining their goals and expected outcomes.

Conclusions. The use of authentic discourses as the natural background is vital for students to reveal form meaning - use connection and associations. Even one example of existing a wide range of obligation/necessity meanings within one context demonstrate the potentiality of increasing student awareness of the obligation (necessity associations, thus framing the study and the further recognition of the forms in close connection with their meanings which, in its turn, provides the continued opportunity for their use.

\section{REFERENCES}

1. Biber D. et al. Longman grammar of spoken and written English. Harlow: Pearson Education Ltd., 2000.

2. Common European Framework of Reference for Languages: Learning, teaching, assessment (CEFR) https://rm.coe.int/16802fc1bf

3. Chomsky N. Aspects of the theory of syntax. Cambridge, MA: MIT Press, 1965.

4. Givón T. Syntax and semantics. Vol. 12: Discourse and Syntax. New York: Academic Press, 1979.
5. Givón T. Topic continuity in discourse: A quantitative cross language study. Amsterdam: John Benjamins, 1983.

6. Halliday M., Hasan R. Language, context and text: A social semiotic perspective. Oxford: OUP, 1989.

7. Quality management systems -Requirements (ISO 9001:2015)

8. Maurer J. Focus on Grammar: An advanced course for reference and practice. N.Y.: Pearson Education, 2000. 